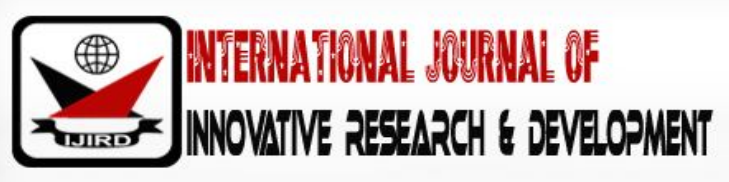

ISSN 2278 - 0211 (Online)

\section{Mentees Perception on the Nature of Teaching Practice and Supervision at the Colleges of Education in Ghana}

\author{
Emma Nsafoah \\ Tutor, Akrokerri College of Education, Science Department, Ghana \\ Charles Agyei Amoah \\ Tutor, OLA College of Education, Science Department, Ghana \\ Nathan Ohene Gyang \\ Tutor, Akrokerri College of Education, Science Department, Ghana
}

\begin{abstract}
:
The purpose of the study is to find out the nature of teaching practice supervision and the mentees perception on the roles of the supervisors in teaching practice.The descriptive survey design was used for the study. The target population used for the study consisted of all 2017 third year students (mentees) of Colleges of Education in Ghana while the accessible population consisted of 2017 third year mentees from Akrokerri College of Education. Simple random sampling was used to select a sample of 153 for the study. The instrument used was questionnaire. It was found out that pre-observation was partially done. Few supervisors sit in to observe a full lesson during the observation stage. Majority of the respondents were of the view that during the post-observation conference, discussions are held during which set targets are reviewed and supervisors provide guidance and suggestions for improvement. Majority of the respondents are also not given the chance to make comments on their performance. Again, majority of the supervisors - mentors, lead mentors and link tutors do perform their roles as stipulated in the In-In-Out Policy Document. These include vetting of lesson notes, provision of professional growth and guidance and working in collaboration among others. Few mentors, however, assume that the vetting of lesson notes by lead mentors were not enough. It was recommended that teachers must be made to do full pre-observation and sit throughout the lesson to supervise the mentees.
\end{abstract}

Keywords: Mentors, lead mentors, mentees, link tutors

\section{Introduction}

The quality of human capital of a nation depends on the quality of education it offers. This quality of education is determined by the quality of teachers. Thus, the standard of teachers must be kept abreast with the current expansion in knowledge and advancement in technology. Unfortunately, teacher education in Ghana has not received much attention as compared to education at school level, despite inadequate numbers of trained teachers and poor quality of teaching and learning outcomes (Pecku, 1998)). It is therefore imperative to give a high priority to teacher education during the implementation of educational reforms.

The Ministry of Education (MOE) has been embarking on some educational reform activities with regard to the structure and content of teacher education in Ghana; though such reforms have failed to make the issue of teacher quality and its development the cornerstone of the strategy to improve teacher education in Ghana.

One of the educational reforms that rather considered teacher quality is the Free Compulsory Universal Basic Education (FCUBE) programme or policy. One of the objectives of the FCUBE policy is to improve the quality of teaching and learning in Basic Education. In Ghana, one of the strategies of this objective is to enhance specific teaching skills through preservice and school based in-service training of teachers.

The current practice in teacher education has therefore moved away from the situation where teacher education institutions see themselves as solely responsible for training teachers. Goodlad (1990) further remarked that teacher education now relies greatly on the use of apprenticeship or internship model of training. This model offered the teacher trainee, a substantial school experience. It can therefore be seen that the In-In-Out Programme was implemented in October 2001 when the former programme was found to be inadequate for teacher trainees to acquire the required pedagogical skills for teaching. It was incorporated in the new pre-service diploma in Basic Education introduced in 2004 to replace the 3-year Post Secondary Programme. 
The In-In-Out Programme is meant to produce qualified and effective teachers for basic schools through competencybased training. It emphasizes the integration of content with methodology leading to the development of practical teaching skills. As the name suggests, the first two years (the In-In period) are spent on the college campuses whilst the third year (Out period) is spent outside the college campuses. Student trainees return to campuses for about four weeks at the end of the academic year to review their field experiences and go through a final assessment.

The In-In-Out Programme is highly beneficial to the trainee. Yet the trainee is faced by challenges that require investigation. One of such challenges is the mentees concern on supervision, which involves various people. These people are mentors, lead mentors and link tutors (GES, 2001). The mentors and lead mentors are to serve as guides and counsellors to the mentees.

Mentors are the classroom teachers who are to supervise and work closely with mentees. They are to operate as inschool supervisors providing regular on-the-spot professional guidance and encouragement to the mentees (In-In-Out Policy Document, 1999). The document states that mentors should be experienced and trusted advisors to the mentees.

The lead mentors are the head teachers of the schools of attachment. The lead mentors are supposed to co-ordinate the work of the mentors and prepare comprehensive reports on the mentorship programme, in consultation with all the mentors.

The link tutors are the college of education tutors who supervise classroom work as well as project work of mentees. They are to provide linkage between the colleges of education and schools of attachment to ensure that the practical training of the mentees is in consonance with the goals of competency-based teacher education. The document indicates that the link tutors are supposed to work closely with mentors upon their visits to resolve any problem that mentees might have experienced and can contribute to the effectiveness of the craft of teaching when they direct the mentees to pay attention to the theory underlying the teaching process. The link tutors should be persons of good standing in college and should have displayed the ability to share the feelings and experiences of mentees, with the aim of helping them to acquire the skills of teaching. It continued that a link tutor should be assigned to one cluster of teaching practice sites, paying a visit each week within a month, though visits can be as and when needed. These link tutors are to hold meetings with mentors and decide with them the necessary actions to take to support the mentees effectively.

The In-In-Out Programme is also underpinned by two key concepts; namely, school-focused Practice Teaching and Mentorship (GES, 2001). The aim of the school-focused studies is to offer first-hand experience and insight into the ways of dealing with the everyday practical problems of schools.It is the "Out" component of the In-In-Out Programme that involves attachment to school and supervision as well as mentorship. These demands pose certain issues or challenges to all stakeholders. An issue that has surfaced following investigation into the challenges that confront teacher trainees is their perception on the supervisory roles of mentors as recommended by Ankuma (2006).

It can be seen that teaching practice forms a major component of the course of teacher training institutions. In the view of Olaitan and Agusiobo (1981) teaching practice is the first opportunity for teacher trainees to take part in real classroom situation and therefore should provide opportunity for guidance. This guidance is achieved through mentorship and supervision.

Supervision as a major aspect of teaching practice and the Out component of the In-In-Out in general has certain demands, which may pose challenges. Among the challenges are the supervisory roles of mentors as perceived by mentees (Ankumah, 2006). The mentors who serve as supervisors are specifically mentors, Lead mentors and link tutors (GES, 2002). The In-In-Out policy document, the different categories of supervisors have specific roles to play in the supervision process. How the supervisors carry their duties will determine the nature of supervision. It appears from a review of the literature that much studyhas not been conducted on mentees perception on the nature of teaching practice and supervision in Ghana.

\section{Statement of the Problem}

It can be seen that teaching practice forms a major component of the course of teacher training institutions. In the view of Olaitan and Agusiobo (1981) teaching practice is the first opportunity for teacher trainees to take part in real classroom situation and therefore should provide opportunity for guidance. This guidance is achieved through mentorship and supervision.

Supervision as a major aspect of teaching practice and the Out component of the In-In-Out in general has certain demands, which may pose challenges. Among the challenges are the supervisory roles of mentors as perceived by mentees (Ankumah, 2006). The mentors who serve as supervisors are specifically mentors, Lead mentors and link tutors (GES, 2001). There is therefore the need to assess the nature of teaching practice supervision and the mentee's perceptions of the role of supervisors in teaching practice.

\subsection{Purpose of the Study}

The purpose of the study is to find out the nature of teaching practice supervision and the mentees perception on the roles of the supervisors in teaching practice. 


\subsection{Research Questions}

- What is the nature of teaching practice supervision?

- What are mentees perceptions on the roles of the supervisors in teaching practice?

\section{Methodology}

The descriptive survey design was used for the study. The target population used for the study consisted of all 2017 third year students (mentees) of Colleges of Education in Ghana while the accessible population consisted of 2017 third year mentees from Akrokerri College of Education. The accessible population was made up of six (6) classes: Diploma in Basic Education (DBE) Class 3A, DBE Class 3B, DBE Class 3C, DBE Class 3D, DBE Class 3E and DBE Class 3F with a total of 383. DBE Class 3A and Class 3B read Physical Education as elective subject, DBE Class 3C read Vocational Skills, DBE Class 3D read Agricultural Science, DBE Class 3E read Religious and Moral Education and DBE Class 3F read Art. Simple random sampling was used to select a sample of 153 for the study.

The tool used in the data collection was questionnaire. The instrument sought information on the perception of mentees on the supervisory roles of mentors during supervision with regards to:

- $\quad$ The nature of teaching practice supervision

- Mentees perceptions on the roles of the supervisors

The researcher conducted a pre-testing to fine-tune the instrument. To validate the content of the instrument used, it was subjected to supervisors' scrutiny and comments. The researcher personally administered the questionnaire to the mentees. The reliability of the instrument was computed using the Cronbach-co-efficient alpha. The alpha value was 0.77.

\section{Results/ Discussion}

The purpose of the study was to find out the nature of teaching practice supervision and the mentees perception on the roles of the supervisors in teaching practice.

Research question one was stated as "What is the nature of teaching practice supervision? The items framed to obtain responses to research question one was in three sections. These were: Pre-observation conference; Observation and Postobservation conference. These three sub-headings are three of the five stages of clinical supervision. The other two are the Analysis and strategy and Post-conference analysis stages, (Stages 3 and 5), which involve the supervisors only and therefore were not considered. Mentees' responses to questions on pre-observation stage during supervision are presented in Table 1.

\begin{tabular}{|c|c|c|c|c|}
\hline Statements & A & \% & DA & \% \\
\hline Prior information given & 29 & 19.0 & 124 & 81.0 \\
Hold discussions with supervisors before lesson observation & 30 & 19.6 & 123 & 80.4 \\
Establishment of cordial relationship with supervisors & 59 & 38.6 & 114 & 61.4 \\
Information about class given & 39 & 25.5 & 114 & 74.5 \\
Gives information on lesson & 31 & 20.3 & 122 & 79.7 \\
Set targets & 39 & 25.5 & 144 & 74.5 \\
Informed that comments will be taken & 65 & 42.5 & 88 & 57.5 \\
\hline
\end{tabular}

Table 1: Mentees' Responses on Pre-Observation Stage

Key to the Table: A - Agree; DA - Disagree; \% - Percentage of Respondents

The data in Table 1 represents the mentee's perception on the pre-observation stage of supervision. One hundred and twenty-four mentees representing $81.0 \%$ said they were not given prior information before supervision. This shows that supervision still seems to be traditional as formerly when supervisors parked their vehicles at distances away from schools and tiptoed to the classrooms; thus, visits were unannounced (Eye, 1975). This situation pertains perhaps because mentees are informed at the onset of the practice to be ready at any time for supervision. Sometimes, the information is sent from the College to mentees. From the table, 29 mentees (19.0\%) agreed that prior information was given before supervision. It could be that those that do not receive such information are in remote areas and therefore accessibility is difficult or the bearers of the information do not send the message.

While 30 mentees (19.6\%) said they have discussions with their supervisors before lesson observation, 123 mentees representing $80.4 \%$ responded to the contrary. Such conferences according to Brickell (1961) offer supervisors the opportunity to familiarize themselves with what pertains in the school situation. He added that during such meetings the objectives of the supervision is made clear to the supervisee and there is establishment of good rapport. This reveals that the pre-observation meetings enable the supervisors to give a judgment that is a true reflection of mentees performance thereby eliminating any biasness or partiality. Once such conferences are not held, it is obvious that what should take place at the meeting does not occur. This is reflected in the table as majority of the mentees said they do not give information about class to be taught (74.5\%), lesson to be taught (79.7\%) and no targets are set (74.5\%). The establishment of a cordial relationship does not have direct link with discussions held, hence the trend it shows seem to be quite different. The number of mentees that said cordial relationship is not established was 94 representing $61.4 \%$. Though 88 mentees (57.5\%) said that they were 
not informed that notes and comments would be taken by the supervisor during observation, it must be emphasized that teacher trainees are made aware of this before they go on attachment for teaching practice. Concerning the set targets, mentees are made aware of the assessment form and what it entails. Perhaps this explains why supervisors do not pay attention to these areas. It can be seen that the pre-observation conference is either not done or partially done.

\begin{tabular}{|c|c|c|c|c|}
\hline Statements & A & \% & DA & \% \\
\hline Supervisors Enter Class Unnoticed & 68 & 44.4 & 85 & 55.6 \\
Supervisors Avoid Eye Contact & 87 & 56.9 & 66 & 43.1 \\
Supervisors Sit In Full View Of Class & 137 & 89.5 & 16 & 10.5 \\
Supervisors Take Notes & 140 & 91.5 & 13 & 8.5 \\
\hline
\end{tabular}

Table 2: Mentees' Responses on Observation Stage

Key to the Table: A - Agree; DA - Disagree; \% - Percentage of Respondents

Data from Table 2 shows that 68 mentees representing $44.4 \%$ indicated that their supervisors entered the classrooms unnoticed. Entering the class unnoticed will be quite difficult to achieve due to the classroom setting where doors are usually positioned near the chalkboard. Eighty-seven mentees representing $56.9 \%$ said they have eye contact with their supervisors during supervision. This could be due to the fact that such mentees are too much conscious of the presence of the supervisors. This notwithstanding, avoiding eye contact will be difficult to control. Supervisors are to sit in full view of the class in order to assess the situation and so majority of the mentees, that is, 137 representing $89.5 \%$ and 140 representing $91.5 \%$ said their supervisors sit in full view of the class and take notes respectively. This does not appear to pose problems since it is the same even in traditional supervision.

\begin{tabular}{|c|c|c|c|c|}
\hline Statements & A & $\mathbf{\%}$ & DA & $\mathbf{\%}$ \\
\hline Discussions Held After Observation & 135 & 88.2 & 18 & 11.8 \\
Review Of Set Targets & 119 & 77.8 & 34 & 22.2 \\
Given Chance To Comment & 61 & 39.9 & 92 & 60.1 \\
Provides Guidance And Suggestions & 85 & 55.6 & 68 & 44.4 \\
Prepares Lesson Notes Again & 67 & 43.8 & 86 & 56.2 \\
\hline
\end{tabular}

Table 3: Mentees' Responses on Post-Observation Conference

Key to the Table: A - Agree; DA - Disagree; \% - Percentage Of Respondents

Table 3 is on the post-observation conference. It can be observed from the Table 3 that 135 mentees representing $88.2 \%$ confirmed that discussions were held after observations. This is what usually pertains at the Colleges of Education. Eighteen mentees (11.8\%), however, disagreed that discussions were held after observation. Though the Educational Reforms Report in 2002 stipulates that post-observation conferences are held in few cases, this study has proved otherwise, indicating that post observation conferences are held. Thus, supervision is gradually shifting from the traditional to a clinical one. Discussion is needed for improvement in subsequent lessons and this is confirmed by Sergiovanni and Starratt (1998) Johnson (1998). During such discussions it is obvious that targets, once set, will be reviewed and this is confirmed by 119 mentees (77.8\%) who agreed that set targets are reviewed. Ninety-two mentees representing $60.1 \%$ said they were not given the chance to comment on their performance while 61 mentees representing $39.9 \%$ agreed. Half of the number said they were given guidance and suggestions and almost half, that is $43.8 \%$ said they were made to prepare lesson notes again. Usually such supervision is done by the link tutors, that is, College of education tutors, who go there on visits and, time may be a limiting factor, hence this result.

It can be seen that supervision is not wholly clinical neither is it entirely traditional. There seem to be a situation where some supervisors are adhering to traditional supervision rather than to clinical supervision indicating that the transition is not complete. This may be due to the fact that there is an aspect of assessment or evaluation in this supervision. The third and fifth (last) stages of clinical supervision are absent because these stages are carried out by the supervisor alone and it will be difficult for mentees to give their perception about them. However, these stages might have an effect on the subsequent stages.

In sum, research question one suggests that pre-observation is partially done. Few supervisors sit in full view of class and take notes during the observation stage. Majority of the respondents are of the view that during the post-observation conference, discussions are held during which set targets are reviewed and supervisors provide guidance and suggestions for improvement. Majority of the respondents are also not given the chance to make comments.

\subsection{Research Question Two: Roles of Supervisors}

The following sections provide answers to the second research question, "What are mentees perceptions on the roles of the supervisors?". The responses given are presented in Tables 4-6under the following sub-headings: Roles of Mentors: Roles of Lead Mentors and Roles of Link Tutors. 


\begin{tabular}{|c|c|c|c|c|}
\hline Statements & A & \% & DA & \% \\
\hline Vets lesson notes & 84 & 54.9 & 69 & 45.1 \\
Regular to school & 119 & 77.8 & 34 & 22.2 \\
Stays in class & 114 & 74.5 & 39 & 25.5 \\
Teaches during his/ her period & 132 & 86.3 & 21 & 13.7 \\
Provides professional growth and guidance & 113 & 73.8 & 40 & 26.2 \\
Works cooperatively & 126 & 82.4 & 27 & 17.6 \\
\hline
\end{tabular}

Table 4: Mentees' Views on the Roles of Mentors

Key to the Table: A - Agree; DA - Disagree; \% - Percentage of Respondents

Table 4 represents mentees' responses concerning the role of mentors. Mentors, who are regular class teachers, are required to vet lesson notes, be regular at school, teach their periods designated to them and provide professional growth and guidance to mentees. It can be gathered from Table 4 that majority of the respondents agree or confirm that these were done. In each instance percentages of more than 50 were recorded. The few who failed to do this may be those who are not committed to their work or who take the mentees' teaching practice for granted or sees it as a means of holiday for themselves. Sixty-nine respondents representing $45.1 \%$ said their mentors do not vet their lesson notes. Usually the lesson notes are vetted by the head teachers who are the lead mentors and the mentors who are the class teachers may sometimes assume that what the lead mentors have done is enough. Adentwi (2002), however, asserted that both mentors and lead mentors are required to vet lesson notes. Thus, mentors should be made aware of the need to perform this role. Cooperative work among mentors stems from the establishment of a good interpersonal relationship among members of staff. It can therefore be concluded that the majority of mentors do their work of vetting lesson notes, being regular to school, staying in class, teaching their periods designated to them and providing professional growth and guidance to mentees as required.

\begin{tabular}{|c|c|c|c|c|}
\hline Statements & A & \% & DA & \% \\
\hline Vets lesson notes & 109 & 71.2 & 44 & 28.8 \\
Provides professional growth and guidance & 99 & 64.7 & 54 & 35.3 \\
Reports on mentorship & 74 & 48.3 & 79 & 51.7 \\
Coordinates work of mentors & 107 & 70.0 & 46 & 30.0 \\
\hline
\end{tabular}

Table 5: Mentees' Views on the Roles of Lead Mentors

Key to the Table: A - Agree; D - Disagree; \% - Percentage of Respondents

From Table 5, 109 mentees representing 71.2\% indicated that their lesson notes are vetted by lead mentors, 44 mentees representing $28.8 \%$ said their lesson notes are not vetted. Ninety-nine mentees representing $64.7 \%$ said they receive professional growth and guidance from their lead mentors as against 54 mentees representing $35.3 \%$. This is very important since such a role will help build up the competencies of trainees. The reports on mentorship are required by the College and so the 79 mentees (51.7\%) who said that their lead mentors do not prepare reports on their mentorship programmes may not be aware of this. Usually the lead mentees are those required to keep most records like attendance to school and study circle meetings among others, thus most mentees may or may not have such information. It is also the duty of the lead mentor to coordinate the work of all the mentors in order to provide a true and proper report on mentorship programmes of individual mentees and this is confirmed by 107 mentees (70.0\%) who indicated that lead mentors coordinate the work of mentors. It can therefore be inferred that generally lead mentors also perform their roles as expected.

\begin{tabular}{|c|c|c|c|c|}
\hline Statements & A & \% & DA & \% \\
\hline Vets lesson notes & 82 & 53.6 & 71 & 46.4 \\
Provides professional growth and guidance & 103 & 67.3 & 50 & 32.7 \\
Collaborates with mentors and lead mentors & 88 & 57.5 & 65 & 42.5 \\
\hline
\end{tabular}

Table 6: Mentees' Views on the Roles of Link Tutors

Key to the Table: A - Agree; DA - Disagree; \% - Percentage of Respondents

Concerning vetting of lesson notes and collaborating with mentors and lead mentors, about half of the respondents agree that link tutors do play these roles. This is shown by $53.6 \%$ for vetting of notes and $57.5 \%$ for collaborative working. Majority of the respondents, 103 mentees representing 67.3\% said they receive professional growth and guidance from the link tutors. From the above findings, it can be concluded that majority of the link tutors perform their roles vetting of lesson notes, providing professional growth and guidance to mentees and collaborating with mentors and lead mentors as required.

The answers to research question two are that majority of the supervisors - mentors, lead mentors and link tutors do perform their roles as spelt out in the In-In-Out Policy Document. These include vetting of lesson notes, provision of professional growth and guidance and working in collaboration among others. Few mentors, however, assume the vetting of lesson notes by lead mentors is enough. 


\section{Conclusions}

It is concluded that pre-observation is partially done. Few supervisors sit in to observe a full lesson during the observation stage. Majority of the respondents were of the view that during the post-observation conference, discussions are held during which set targets are reviewed and supervisors provide guidance and suggestions for improvement. Majority of the respondents are also not given the chance to make comments.

Again, that majority of the supervisors - mentors, lead mentors and link tutors do perform their roles as spelt out in the In-InOut Policy Document. These include vetting of lesson notes, provision of professional growth and guidance and working in collaboration among others. Few mentors, however, assume that the vetting of lesson notes by lead mentors is not enough.

\section{Recommendations}

- Teachers must be made to do full pre-observation and sit throughout the lesson to supervise.

- Lead mentors must be made to vet the lesson notes of students frequently.

\section{References}

i. Adentwi, K. I. (2002). Principles, practices and issues in teacher education. Kumasi: Skies Printing Works

ii. Ankuma, M. (2006). Challenges facing teacher trainees in the mentorship programme in the Ashanti Region of Ghana. University of Cape Coast, Cape Coast: Anunpublished M. Phil.Thesis

iii. Brickel, H. M. (1961). Organising New York State for educational change. New York: State Education Department

iv. Ghana Education Service Council (2001). Status report on the "out" component of the In-In-Out Programme. Accra: Ghana education service.

v. Eye, G. G. (1975). Problems in supervision. The Canadian Administrator, 15, (9), 19-20

vi. Goodlad, J. (1990). Teachers for our nation's schools. California: Jossey-Bass

vii. Johnson, S. D. (1998). An alternate vision for assessment in vocational teachers education. Columbia: University of Missouri

viii. Olaitan, S. O. \& Agusiobo, O. N. (1981). Principles of practice teaching. Ibadan: Spectrum Book Ltd

ix. Pecku, N. K. (1998). Teacher education in Ghana: Evolution and prospects. Accra:Elorm Electronics \& Business Services.

x. Sergiovanni, T. J. \& Starrat, R. J. (1998). Supervision: A redefinition. (6 $6^{\text {th }}$ ed). Boston: McGraw-Hill $\quad$ Companies Inc. 